\title{
Socioeconomic inequalities in self- perceived oral health among adults in Chile
}

Francisco Gallego ${ }^{1}$, Cristián Larroulet ${ }^{2}$, Leonor Palomer ${ }^{3}$, Andrea Repetto ${ }^{4^{*}}$ (D) and Diego Verdugo ${ }^{5}$

\begin{abstract}
Background: This paper studies the socioeconomic disparities in self-perceived oral health among Chilean adults and in the perceived physical, functional, psychological and social consequences of oral health.

Methods: In February 2011, 1,413 residents of Metropolitan Area of Santiago, Chile, were interviewed using a standardized questionnaire and examined by dentists for dental status and oral health conditions. Only adults 18 to 60 years old affiliated with the public healthcare system were eligible to participate. We estimate socioeconomic gradients in self-perceived oral health and its distinct dimensions. We use the Heckman two-step procedure to control for selection bias given the non-random nature of the sample. In addition, we use a two-equation ordered response model given the discrete nature of the dependent variable.
\end{abstract}

Results: There is a non-linear socioeconomic gradient in self-perceived oral health even after controlling for oral health status. The gradient is steep at the lower end of the income distribution and constant at mid-income levels. These socioeconomic disparities are also found for the psychological and social dimensions of self-perceived oral health, but not for the functional limitations and physical pain dimensions.

Conclusions: The findings are consistent with inequities in the access to oral health services due to insufficient provision in the public sector and costly options in the private sector.

Keywords: Chile, Health-related quality of life, Socioeconomic gradients, Inequality

JEL classification: 114, 115, C21, C26

\section{Background}

Oral health disorders impact everyday life and the quality of life on multiple dimensions $[1,2]$. Poor oral health is associated with functional limitations, pain and low selfesteem $[3,4]$, as well as with a number of general health conditions [5]. Other less studied dimensions such as labour market opportunities also relate to oral health [6].

Oral health-related quality of life depends crucially on the way individuals perceive oral conditions translating into their daily lives. For example, a poor oral condition might lead to eating difficulties and have a negative impact on nutritional intake $[7,8]$; it might translate into functional limitations due to discomfort, restricting activities like work or study [2,9]; and it might translate

\footnotetext{
* Correspondence: andrea.repetto@uai.cl

${ }^{4}$ School of Government, Universidad Adolfo Ibáñez, and Núcleo Milenio Modelos de Crisis (NS 130017), Diagonal Las Torres 2640, 234A Peñalolén, Santiago, Chile

Full list of author information is available at the end of the article
}

into reduced social interactions due to shame over missing teeth or chronic bad breath $[10,11]$.

This paper aims to study socioeconomic inequalities in the subjective assessment of oral health among adults in Chile. We emphasize the role of socioeconomic background since much of the observed variability has been related to factors like education and income [12]. Specifically, we examine the independent contribution of these socioeconomic factors in explaining self-perceived oral health (SPOH) after adjusting for oral health status and other determinants. We also study socioeconomic gradients in the distinct dimensions of SPOH: that is, in the perceived physical, functional, psychological and social consequences of oral health.

Most of the studies on oral health gradients have been conducted in developed countries where public healthcare is relatively strong and where the private sector plays a very important role in the provision and financing of 
dental care [13]. Even in these contexts the literature consistently finds a significant socioeconomic gradient. For instance, Sanders et al. [4], Locker [12], Wamala et al. [14] and Sabbah et al. [15] find steep gradients in oral health among adults in Australia, Canada, Sweden and the United States, respectively. Interestingly, in one of the few studies for developing countries, Gabardo et al. [16] find no association between oral health perceptions and household income among adults in Brazil.

The provision of public oral health services in Chile is quite limited, as it mainly offers primary services to pregnant women, 6-year-old children and 60-year-old adults who are covered by public health insurance, in addition to basic outpatient emergency services [17]. This limited provision of public services addressing complex problems is combined with an active private sector that offers costly services of heterogeneous quality. According to the study conducted by Vásquez, Paraje and Estay [18], the organization of the oral health care system in Chile has led to a markedly pro-rich inequity in dental visits.

Although the private sector also plays an important role in the provision of dental care in developed countries, the coverage of public insurance programs and of the public provision of oral health services tend to be much more extended in those countries than in Chile [19]. Consequently, differences in the structure of the dental healthcare system may lead to differences in the observed socioeconomic gradients.

Thus, this study has three objectives: first, to assess whether socioeconomic status accounts for differences in oral health perceptions in the adult Chilean population; second, to assess the shape of the gradient; and third, to examine the socioeconomic disparities in the physical, functional, psychological and social dimensions of $\mathrm{SPOH}$.

\section{Data and methods}

\section{Study population and sampling}

In February 2011, 1,413 residents of the Greater Santiago area were enrolled in a program offering free dental care services, including dental prosthetics. ${ }^{1}$ The target population included all adults between the ages of 18 and 60 and affiliated with the public healthcare system. Enrolment was non-random as participants responded to advertisements published in mass media.

To participate in the program, individuals had to first apply by phone or by registering online. They were then asked to attend a meeting at the Pontificia Universidad Católica's San Joaquín Campus in Santiago.

After obtaining informed consent, trained staff administered a questionnaire and qualified dentists conducted an extensive dental examination. The protocol was approved by the Human Ethics and Research
Committee of the Pontificia Universidad Católica de Chile Economics Department.

\section{Study measures}

The questionnaire collects information on demographic and socioeconomic characteristics (age, sex marital status, number and age of children, employment and education) as well as on oral health behaviour, such as frequency of daily tooth brushing and the time since the last dental appointment. The survey also collects information on self-perceived oral health and self-esteem.

To measure oral health-related quality of life, each participant answered the 14 questions of the Oral Health Impact Profile (OHIP-14) developed by Slade [20], translated into Spanish and validated by López and Baelum [21] in a Chilean population. The instrument collects information on seven dimensions: Functional Limitations, Physical Pain, Psychological Discomfort, Physical Disability, Psychological Disability, Social Disability, and Handicap. Questions are answered on a five-point Likert scale. Scores range between 0 and 56; a higher score indicates a worse perceived oral health-related quality of life.

To measure self-esteem, we use the Rosenberg SelfEsteem Test [22], validated for Chilean adults by RojasBarahona et al. [23]. The instrument consists in 10 statements on overall feelings of self-worth evaluated on a four-point Likert scale. Scores range between 10 and 40; a higher measure indicates a higher global self-esteem.

The dental examination that followed the interview was conducted on the basis of protocols designed by the World Health Organization [24]. Dentists collected information on the status of each tooth (healthy, caries, missing, etc.) as well as on other conditions such as periodontal disease, gingivitis and dental occlusion problems.

This dataset is complemented with data from the nationally representative 2011 CASEN survey, which collects rich information on the socioeconomic characteristics of Chilean households [25].

\section{Statistical analysis}

We use regression methods to estimate socioeconomic gradients in perceived oral health; i.e., we estimate a model like

$$
y_{1}=x_{1} \beta_{1}+x_{2} \beta_{2}+u_{1}
$$

where $y_{1}$ is a measure of self-perceived oral health, $x_{1}$ is a vector of socioeconomic variables, $x_{2}$ is a vector of control variables and $u_{1}$ is an error term. We are interested in estimating the parameters in vector $\beta_{1}$. Standard OLS techniques may not be appropriate in this case for two reasons: (1) the discrete and ordinal nature of the dependent variable, and (2) the non-random nature of the sample. 
When addressing the first problem, it is worth noting that our main dependent variable has 57 categories. A number of simulation studies have shown that when the number of ordered categories is relatively high (i.e., five or more), the dependent variable can be treated as continuous without significant losses in terms of the statistical properties of the estimates [26-28]. Therefore, linear models such as OLS provide accurate estimates in many situations. Even so, in addition to the linear model in Eq. (1), we also estimate an ordered multinomial response model [29]. The model assumes that there is an unobserved latent outcome variable $y^{*}$ [30]:

$$
y^{*}=x_{1} \gamma_{1}+x_{2} \gamma_{2}+u_{2}=x^{\prime} \gamma+u_{2}
$$

However, we do observe $y_{1}$ such that

$$
y_{1}=j \text { if } \mu_{j-1}<y^{*} \leq \mu_{j}
$$

where $j=0,1,2, \ldots, J, \mu_{0}=-\infty$ and $\mu_{J}=\infty$. The unknown $\mu$ parameters are estimated along with the $\gamma$ parameters, assuming $u_{2}$ follows a standard normal distribution. That is,

$$
\operatorname{Pr}\left[y_{1}=j\right]=\Phi\left(\mu_{j}-x^{\prime} \gamma\right)-\Phi\left(\mu_{j-1}-x^{\prime} \gamma\right)
$$

where $\Phi$ represents the standard normal cumulative distribution function. It is worth emphasizing that each $\gamma$ coefficient represents the marginal effect of the corresponding regressor on the latent measure of self-rated oral health $y^{*}$, and not on the observed outcome $y_{1}$. Thus, the OLS estimates and the ordered response model coefficients are not directly comparable; i.e., the coefficients of the latter model must be interpreted with care. Another limitation of non-linear models is that the researcher needs to assume a specific distribution, an assumption that is not testable and that may not be accurate to the specific problem [31].

With all this in mind - that is, because the choice between linear and ordered response models is not a priori clear - below we report the estimation results for both the linear and the ordered response models. In addition, estimating both models allows us to analyse the robustness of our results to the empirical strategy given the models' different underlying assumptions.

With respect to the non-random nature of the sample, a non-representative sample leads to biased estimates if sample selection is the result of unobservable characteristics that are associated with both participation and outcomes. Since individuals had to first apply and then travel to campus to participate in the study, it is plausible that SPOH and individual choice of whether or not to participate are correlated. We use a two-equation procedure to correct for potential sample selection bias.
That is, we also estimate an equation that models participation in the sample:

$$
y_{2}=1\left[x_{1} \delta_{1}+x_{3} \delta_{3}+v_{2}>0\right]
$$

where $y_{2}$ is an indicator variable denoting whether an individual is observed (i.e., is in the baseline sample), $x_{3}$ is a set of variables that affect the participation decision and $v_{2}$ is an error term. We assume that $v_{2}$ follows a normal distribution and estimate a probit model for this equation. To do so, we combine the baseline survey with a representative sample from the 2011 CASEN survey consisting in all individuals who comply with the eligibility criteria to participate in the study. To ensure identification, we include in $x_{3}$ variables that are excluded from $x_{2}$-i.e., instrumental variables that are related to participation but which have no independent effect on selfperceived oral health. We use variables measuring the proximity to information sources on the program, in addition to the time-cost of traveling to the University campus, as instruments.

Estimating the participation equation using a probit model produces an estimate of the inverse of the Mills ratio (IMR). When the model for $\mathrm{SPOH}$ is linear, it can be shown that under certain assumptions the estimation of Eq. (1) including the IMR as a control variable yields parameter estimates that are consistent. Moreover, the statistical significance of the estimate of the IMR coefficient serves as a test for the null of no sample selection [30, 32].

When estimating the ordered response model, we assume that the errors $u_{2}$ and $v_{2}$ follow a bivariate normal distribution with correlation coefficient $\rho$. We use maximum likelihood estimation methods to jointly estimate the outcome and participation equations. A likelihood ratio test comparing the log likelihood of the joint model with the sum of the log likelihoods for the ordered response and participation models yields a test of the null hypothesis of no sample selection [33].

Finally, we use Chi-squared tests comparing the coefficients in vector $\beta_{1}$ in the linear model and the coefficients in vector $\gamma_{1}$ in the ordered response model to analyse the shape of the estimated gradients.

\section{Selected variables and definitions}

Table 1 displays the variables selected for the model estimation. The dependent variable of the self-perceived oral health equation is the OHIP-14 score. Explanatory variables are classified into two main groups: socioeconomic and demographic characteristics, and clinically assessed oral health. The variables used as instruments for identification are also listed.

Within the first group, we are mainly interested in measures of socioeconomic status. We use two sets of 
Table 1 Selected Variables

\begin{tabular}{|c|c|}
\hline Variable & Definition \\
\hline \multicolumn{2}{|l|}{ Dependent variable } \\
\hline OHIP-14 score & $\begin{array}{l}\text { Self-rated oral-health related quality of life } \\
\text { (0 to 56; higher scores indicate a worse perceived oral health status) }\end{array}$ \\
\hline \multicolumn{2}{|l|}{ Independent variables } \\
\hline \multicolumn{2}{|c|}{ Socioeconomic and demographic characteristics } \\
\hline Sex & Sex: male $=1$ and female $=0$ \\
\hline Age & Participant's age in years at the time of the baseline survey \\
\hline $18-30$ & Age between 18 and 30 years: yes $=1$ and no $=0$ \\
\hline $31-40$ & Age between 31 and 40 years: yes $=1$ and $n o=0$ \\
\hline $41-50$ & Age between 41 and 50 years: yes $=1$ and no $=0$ \\
\hline $51-61$ & Age between 51 and 61 years: yes $=1$ and no $=0$ \\
\hline Head of household & Whether participant is head of his/her household: yes $=1$ and no $=0$ \\
\hline Married/partner & Marital status of participant (married or living with partner): yes $=1$ and no $=0$ \\
\hline Children under 5 & Number of children under age 5 living in the household \\
\hline Children aged 5-18 & Number of children between ages 5 and 18 living in the household \\
\hline Education & Highest educational level attained by participant \\
\hline Middle or less & 8th grade or less: yes $=1$ and no $=0$ \\
\hline Incomplete secondary school & Between 8th and 11th grade: yes $=1$ and no $=0$ \\
\hline Complete secondary school & 12th grade: yes $=1$ and no $=0$ \\
\hline Higher Education & At least some higher education: yes $=1$ and no $=0$ \\
\hline Employed full time & Participant works full time: yes $=1$ and no $=0$ \\
\hline Employed part time & Participant works part time: yes $=1$ and no $=0$ \\
\hline Healthcare system & Health plan within the Public Insurance system \\
\hline Public Insurance A (most vulnerable) & Public insurance plan A: yes $=1$ and no $=0$ \\
\hline Public Insurance B & Public insurance plan B: yes $=1$ and no $=0$ \\
\hline Public Insurance C & Public insurance plan C: yes $=1$ and no $=0$ \\
\hline Public Insurance D (least vulnerable) & Public insurance plan D: yes $=1$ and no $=0$ \\
\hline Public Insurance unknown category & Public insurance plan unknown: yes $=1$ and no $=0$ \\
\hline \multicolumn{2}{|l|}{ Clinically assessed oral health } \\
\hline Any front missing teeth & At least one front missing tooth: yes $=1$ and $n o=0$ \\
\hline Caries & Number of caries \\
\hline Less than 6 & Less than 6 caries: yes $=1$ and no $=0$ \\
\hline $6-11$ & 6 to 11 caries: yes $=1$ and no $=0$ \\
\hline 12 or more & 12 caries or more: yes $=1$ and no $=0$ \\
\hline Teeth lost due to caries & Number of teeth lost because of dental caries \\
\hline Less than 6 & Less than 6 teeth lost: yes $=1$ and no $=0$ \\
\hline $6-11$ & 6 to 11 teeth lost: yes $=1$ and no $=0$ \\
\hline 12 or more & 12 teeth lost or more: yes $=1$ and no $=0$ \\
\hline Malocclusion & Occlusion problems: yes $=1$ and no $=0$ \\
\hline \multicolumn{2}{|l|}{ Instrumental variables } \\
\hline Distance to subway & $\begin{array}{l}\text { Whether there is a subway station within a } 2 \mathrm{~km} \text { radius from } \\
\text { the municipality's population centroid where participant resides: } \\
\text { yes }=1 \text { and no }=0\end{array}$ \\
\hline Travel time to campus & $\begin{array}{l}\text { Travel time in minutes from the municipality's population } \\
\text { centroid where the participant resides to the University Campus }\end{array}$ \\
\hline
\end{tabular}


Table 1 Selected Variables (Continued)

\begin{tabular}{|c|c|}
\hline Tertile 1 & 20 min or less: yes $=1$ and $n o=0$ \\
\hline Tertile 2 & Between 20 and 37 min: yes $=1$ and no $=0$ \\
\hline Tertile 3 & 37 min or more: yes $=1$ and no $=0$ \\
\hline \multicolumn{2}{|l|}{ Other variables of interest } \\
\hline \multicolumn{2}{|l|}{ Oral health and behaviour } \\
\hline Any missing teeth & At least one missing tooth: yes $=1$ and $n o=0$ \\
\hline Any caries & At least one caries (treated or untreated): yes $=1$ and no $=0$ \\
\hline Prosthetic need & Clinically assessed prosthetic need (upper and/or lower): yes $=1$ and no $=0$ \\
\hline Reported daily tooth brushing frequency & Number of times a day the participant brushes teeth \\
\hline Dental visit within past year & At least one dental care visit within the past 12 months: yes $=1$ and no $=0$ \\
\hline Bad or regular self-rated oral health & Bad or regular self-rated oral health: yes $=1$ and no $=0$ \\
\hline Rosenberg self-esteem scale & Global self-worth scale (10 to 40; higher values indicate higher global self-esteem) \\
\hline
\end{tabular}

variables: educational attainment and the socioeconomic vulnerability categories defined by the Chilean public health insurance system $[34,35] .{ }^{2}$ In Chile, individuals make mandatory contributions to health insurance, choosing between the single public insurance (National Health Fund or Fondo Nacional de Salud, also known as FONASA) and several private health insurance companies (Health Insurance Institutions or Instituciones de Salud Previsional, also known as ISAPREs). FONASA is structured into four plans - from plan A, which covers the most vulnerable individuals, to plan $\mathrm{D}$ for the least vulnerable - depending on income and number of dependents. Plans also differ in co-payment and benefits. The services provided by the ISAPREs are relatively more expensive and only the highest income households take this option. According to the CASEN 2011 survey, $13 \%$ of the population is affiliated with an ISAPRE, and $85 \%$ of those affiliated with the private system belong to households in the top two income quintiles.

Other variables in this group include sex, age and marital status, children in the household and employment status.

Clinically assessed oral health impairments include missing front teeth, number of dental caries, missing teeth due to caries and occlusion problems.

\section{Descriptive statistics}

Table 2 contains summary statistics for the survey.

The sample is mainly comprised of female participants (72\%) who have completed secondary education or higher (65\%), and who are heads of households (70\%). A large fraction of participants self-rate their oral health as poor or regular (98\%), reporting an average OHIP-14 score of 33.29 , consistent with the high prevalence of clinically assessed oral health problems. Almost all respondents have experienced dental caries (98\%) and 92\% have lost at least one tooth over their lifetimes.
According to the Ministry of Health [36], the prevalence of caries in Chilean adults is $99 \%$ and the prevalence of tooth loss ranges between 80 and 99\% depending on age. Despite the frequency of oral health impairments in the sample, only $32 \%$ of participants had visited a dentist during the past year.

Table 2 also reports a mean self-esteem indicator equal to 27.9, a level somewhat lower than the average of 32.5 reported by Rojas-Barahona et al. [23].

\section{Results}

\section{Gradients in self-perceived oral health}

We estimate socioeconomic gradients in $\mathrm{SPOH}$ using both the linear and the ordered response models. Table 3 presents our benchmark estimates of the SPOH determinants. Additional file 1: Table S1 in the appendix shows the estimation results for the participation equation.

The table's first two sets of columns present the estimates of the linear model. The estimated IMR coefficient is marginally significant, indicating that the error terms in the $\mathrm{SPOH}$ and participation equations are weakly correlated. Therefore, the OLS estimates may be inconsistent due to selection bias, but given that the IMR is only marginally significant, it is not surprising that most of the OLS and Heckman two-step estimates are qualitatively similar. In other words, the bias may be relevant for some of the estimated parameters and not relevant for others.

The linear model estimations corrected for sample selection show a socioeconomic gradient in $\mathrm{SPOH}$. The gradient is steep at the lowest socioeconomic category and relatively constant at higher levels. In fact, we cannot reject the hypothesis that the coefficients associated to the FONASA B to D variables are equal to each other $(p=0.88)$. The effect of ascending from FONASA A to a higher plan - evaluated at the point estimate of the FONASA B coefficient - is large and significant, 
Table 2 Descriptive statistics

\begin{tabular}{|c|c|c|c|}
\hline Variable & Mean & SD & $\mathrm{N}$ \\
\hline OHIP-14 score & 33.29 & 12.05 & 1413 \\
\hline \multicolumn{4}{|c|}{ Socioeconomic and demographic characteristics } \\
\hline Sex & 0.28 & 0.45 & 1413 \\
\hline \multicolumn{4}{|l|}{ Age } \\
\hline $18-30$ & 0.16 & 0.37 & 1413 \\
\hline $31-40$ & 0.24 & 0.43 & 1413 \\
\hline $41-50$ & 0.36 & 0.48 & 1413 \\
\hline $51-61$ & 0.25 & 0.43 & 1413 \\
\hline Head of household & 0.70 & 0.46 & 1413 \\
\hline Married/partner & 0.50 & 0.50 & 1394 \\
\hline Children under 5 & 0.21 & 0.47 & 1413 \\
\hline Children aged 5-18 & 0.91 & 1.03 & 1413 \\
\hline \multicolumn{4}{|l|}{ Education } \\
\hline Middle or less & 0.17 & 0.38 & 1394 \\
\hline Incomplete secondary school & 0.19 & 0.39 & 1394 \\
\hline Complete secondary school & 0.45 & 0.50 & 1394 \\
\hline Higher Education & 0.20 & 0.40 & 1394 \\
\hline Employed full time & 0.47 & 0.50 & 1413 \\
\hline Employed part time & 0.20 & 0.40 & 1413 \\
\hline \multicolumn{4}{|l|}{ Healthcare system } \\
\hline Public Insurance A (most vulnerable) & 0.29 & 0.46 & 1413 \\
\hline Public Insurance B & 0.30 & 0.46 & 1413 \\
\hline Public Insurance C & 0.26 & 0.44 & 1413 \\
\hline Public Insurance D (least vulnerable) & 0.14 & 0.34 & 1413 \\
\hline Public Insurance unknown category & 0.01 & 0.12 & 1413 \\
\hline \multicolumn{4}{|l|}{ Clinically assessed oral health } \\
\hline Any missing front teeth & 0.35 & 0.48 & 1413 \\
\hline \multicolumn{4}{|l|}{ Caries } \\
\hline Less than 6 & 0.84 & 0.37 & 1413 \\
\hline $6-11$ & 0.14 & 0.35 & 1413 \\
\hline 12 or more & 0.02 & 0.14 & 1413 \\
\hline \multicolumn{4}{|l|}{ Teeth lost due to caries } \\
\hline Less than 6 & 0.44 & 0.50 & 1413 \\
\hline $6-11$ & 0.31 & 0.46 & 1413 \\
\hline 12 or more & 0.25 & 0.43 & 1413 \\
\hline Malocclusion & 0.81 & 0.40 & 1413 \\
\hline \multicolumn{4}{|l|}{ Instrumental variables } \\
\hline Distance to subway & 0.50 & 0.50 & 1413 \\
\hline \multicolumn{4}{|l|}{ Travel time to campus } \\
\hline Tertile 1 & 0.49 & 0.50 & 1413 \\
\hline Tertile 2 & 0.41 & 0.49 & 1413 \\
\hline Tertile 3 & 0.10 & 0.30 & 1413 \\
\hline
\end{tabular}

Other variables of interest

Oral health and behaviour
Table 2 Descriptive statistics (Continued)

\begin{tabular}{llll}
\hline Any missing teeth & 0.93 & 0.26 & 1413 \\
Any caries & 0.98 & 0.14 & 1413 \\
Prosthetic need & 0.84 & 0.37 & 1413 \\
Reported daily tooth brushing frequency & 2.75 & 0.87 & 1413 \\
Dental visit within past year & 0.32 & 0.47 & 1413 \\
Bad or regular self-rated oral health & 0.98 & 0.14 & 1413 \\
Rosenberg self-esteem scale & 27.94 & 4.42 & 1413 \\
\hline
\end{tabular}

Abbreviation: $S D$ standard deviation, $N$ number of observations

equivalent to a drop of about 3.2 points in OHIP-14 scores $(95 \% \mathrm{CI}(-5.00,-1.34)$, and $p=0.001)$.

Educational attainment is also related to $\mathrm{SPOH}$ in the two-step linear model even after adjusting for material resources. Each additional educational category leads to statistically significant improvements in oral healthrelated quality of life. For instance, completing secondary school after having only completed middle school reduces SPOH by almost 2.2 points $(95 \%$ CI $(-4.49,0.17)$, and $p=0.069$ ).

The estimation results also suggest that self-perceived oral health is worse among women and that it is negatively correlated with age and with the number of children under 5 years of age in the household.

The last two sets of columns in Table 3 present the ordered response model estimates. It is worth emphasizing that the ordered multinomial response and linear coefficients are not directly comparable: the former measures the effects on the latent continuous self-rated oral health variable, whereas the latter measures the effects on OHIP-14 scores. Nonetheless, the two models yield similar conclusions. First of all, the log-likelihood ratio test is statistically significant, indicating that the error terms in the $\mathrm{SPOH}$ and participation equations are correlated, confirming the results of the Heckman estimates but with a more precise estimator.

Secondly, income is negatively associated with $\mathrm{SPOH}$. Again, the estimated gradient is non-linear, with OHIP14 scores that improve discretely when individuals overcome the lowest income level, but which are constant when higher levels are reached. That is, we cannot reject the hypothesis that the coefficients of the FONASA variables $\mathrm{B}$ to $\mathrm{D}$ are equal to each other $(p=0.61)$. The point estimate of the FONASA B coefficient indicates that the unobserved latent $\mathrm{SPOH}$ variable $y^{*}$ (Eq. (2)) declines by 0.29 points when the individual moves from plan A to plan B (95\% CI $(-0.41,-0.17)$; and $\mathrm{p}<0.001)$.

Third, educational attainment is again significantly and negatively associated with OHIP-14 scores whose point estimates increase as higher education levels are reached.

Finally, female participants have worse self-perceived oral-health, as do those who live in households where 
Table 3 Self-perceived oral health regression results

\begin{tabular}{|c|c|c|c|c|c|c|c|c|}
\hline & \multicolumn{2}{|l|}{ OLS } & \multicolumn{2}{|c|}{ Heckman Two-step } & \multicolumn{2}{|c|}{ Ordered Model } & \multicolumn{2}{|c|}{ Ordered Model Sample Selection } \\
\hline & Coef. & $p$-value & Coef. & $p$-value & Coef. & $\overline{p \text {-value }}$ & Coef. & $p$-value \\
\hline Sex & -3.991 & 0.000 & -2.433 & 0.042 & -0.351 & 0.000 & -0.092 & 0.411 \\
\hline \multicolumn{9}{|l|}{ Age (base: 18-30) } \\
\hline $31-40$ & 3.912 & 0.001 & 2.807 & 0.029 & 0.338 & 0.000 & 0.144 & 0.197 \\
\hline $41-50$ & 5.970 & 0.000 & 4.622 & 0.001 & 0.515 & 0.000 & 0.265 & 0.032 \\
\hline $51-61$ & 7.219 & 0.000 & 6.429 & 0.000 & 0.637 & 0.000 & 0.447 & 0.000 \\
\hline Head of household & 1.522 & 0.038 & -1.506 & 0.456 & 0.161 & 0.008 & -0.270 & 0.049 \\
\hline Married/partner & -0.364 & 0.609 & -0.186 & 0.784 & -0.030 & 0.636 & -0.002 & 0.973 \\
\hline Children under 5 & 2.273 & 0.001 & 2.974 & 0.000 & 0.196 & 0.001 & 0.265 & 0.000 \\
\hline Children aged 5-18 & 0.253 & 0.327 & 0.498 & 0.161 & 0.016 & 0.497 & 0.047 & 0.053 \\
\hline \multicolumn{9}{|l|}{ Education (base: Middle or less) } \\
\hline Incomplete secondary school & -1.184 & 0.217 & -2.162 & 0.069 & -0.113 & 0.182 & -0.231 & 0.004 \\
\hline Complete secondary school & -3.455 & 0.001 & -4.749 & 0.000 & -0.320 & 0.001 & -0.450 & 0.000 \\
\hline Higher Education & -6.031 & 0.000 & -7.206 & 0.000 & -0.536 & 0.000 & -0.623 & 0.000 \\
\hline Employed full time & 0.211 & 0.739 & 1.420 & 0.196 & 0.004 & 0.941 & 0.170 & 0.018 \\
\hline Employed part time & -1.018 & 0.251 & -1.425 & 0.124 & -0.116 & 0.130 & -0.154 & 0.048 \\
\hline \multicolumn{9}{|c|}{ Healthcare system (base: Public Insurance A, most vulnerable) } \\
\hline Public Insurance B & -2.493 & 0.002 & -3.166 & 0.001 & -0.231 & 0.000 & -0.291 & 0.000 \\
\hline Public Insurance C & -2.164 & 0.039 & -3.640 & 0.004 & -0.209 & 0.021 & -0.379 & 0.000 \\
\hline Public Insurance D (least vulnerable) & -2.382 & 0.006 & -3.475 & 0.007 & -0.223 & 0.003 & -0.341 & 0.000 \\
\hline Public Insurance unknown category & -2.131 & 0.172 & 3.431 & 0.771 & -0.262 & 0.053 & 0.518 & 0.204 \\
\hline Inverse Mills ratio (IMR) & & & -4.294 & 0.105 & & & & \\
\hline Constant & 32.623 & 0.000 & 42.148 & 0.000 & & & & \\
\hline Observations & 1,394 & & 1,394 & & 1,394 & & 1,394 & \\
\hline R-squared & 0.138 & & & & & & & \\
\hline LR test indep equations & & & & & & & 6.04 & 0.014 \\
\hline
\end{tabular}

Abbreviations: OLS Ordinary Least Squares, Coef estimated coefficient

The dependent variable is the OHIP-14 score. Independent variables are described in Table 1. The first two columns report OLS estimates without correction for sample selection. The next two correct for sample selection using Heckman's two-step estimator. The third set estimates an ordered multinomial model, whereas the final set corrects the ordered multinomial model for sample selection. Clustered standard errors at the municipality of residence level are reported Inv. Mills ratio (IMR) is the sample selection correction variable in the Heckman model. After estimating the participation equation (Additional file 1: Table S1), for each observation in the sample we compute $\lambda^{\wedge}=\varphi\left(x_{3} \beta_{3}\right) / \Phi\left(x_{3} \beta_{3}\right)$, where $\varphi$ is the density of the Normal Distribution and $\Phi$ is its cumulative

LR test indep equations (likelihood-ratio test) tests hypothesis that the errors of OHIP-14 and participation equations are uncorrelated in the ordered response model

there are children under five years of age. Furthermore, $\mathrm{SPOH}$ worsens with age.

Table 4 presents estimates of the determinants of $\mathrm{SPOH}$ including controls for clinical measures of oral health. The table shows that oral health impairments are important determinants of $\mathrm{SPOH}$ in both sampleselection corrected models. Malocclusion, missing front teeth, a large number of caries and missing teeth due to caries all worsen SPOH independently. In addition, while the age categories are statistically significant in the two-equation estimates in Table 3, they are no longer significant when oral health impairments are included as controls, suggesting that the observed correlation between $\mathrm{SPOH}$ and age is due to decaying oral health status over time.
Regarding socioeconomic inequalities, results in Table 4 show that the income and educational gradients are attenuated once clinically assessed oral health status is controlled for. In the case of FONASA affiliation, we estimate relevant differences in $\mathrm{SPOH}$ between the most vulnerable group and the rest. Importantly, and analogous to our previous estimates, while individuals affiliated with FONASA plans B, C and D are significantly better off than those in plan A, there is no statistically significant difference between them $(p=0.59$ and $p=0.44$ in the Heckman and ordered response models, respectively).

In sum, our findings in Table 4 show that biological factors such as tooth loss are associated with SPOH. However, a central finding is that even after controlling for those biological factors, there is a non-linear socioeconomic gradient 
Table 4 Self-perceived oral health regression results, controlling for oral health condition

\begin{tabular}{|c|c|c|c|c|}
\hline & \multicolumn{2}{|c|}{ Heckman Two-step } & \multicolumn{2}{|c|}{ Ordered Model Sample Selection } \\
\hline & Coef. & $p$-value & Coef. & $p$-value \\
\hline Sex & -2.977 & 0.009 & -0.202 & 0.067 \\
\hline \multicolumn{5}{|l|}{ Age (base: 18-30) } \\
\hline $31-40$ & 0.762 & 0.538 & 0.021 & 0.853 \\
\hline $41-50$ & 0.854 & 0.526 & 0.016 & 0.884 \\
\hline $51-61$ & 0.991 & 0.437 & 0.057 & 0.608 \\
\hline Head of household & -1.079 & 0.573 & -0.170 & 0.248 \\
\hline Married/partner & -0.052 & 0.936 & 0.005 & 0.936 \\
\hline Children under 5 & 2.967 & 0.000 & 0.272 & 0.000 \\
\hline Children aged 5-18 & 0.559 & 0.097 & 0.050 & 0.031 \\
\hline \multicolumn{5}{|l|}{ Education (base: Middle or less) } \\
\hline Incomplete high school & -0.730 & 0.519 & -0.102 & 0.317 \\
\hline Complete high school & -2.650 & 0.022 & -0.281 & 0.002 \\
\hline Higher Education & -4.237 & 0.001 & -0.402 & 0.001 \\
\hline Employed full time & 1.121 & 0.283 & 0.125 & 0.133 \\
\hline Employed part time & -0.973 & 0.267 & -0.120 & 0.148 \\
\hline \multicolumn{5}{|c|}{ Public health system (base: Public Insurance A, most vulnerable) } \\
\hline Public Insurance B & -2.539 & 0.004 & -0.249 & 0.000 \\
\hline Public Insurance C & -2.960 & 0.014 & -0.318 & 0.000 \\
\hline Public Insurance D & -1.930 & 0.115 & -0.213 & 0.005 \\
\hline Public Insurance unknown category & 5.534 & 0.620 & 0.583 & 0.097 \\
\hline Any frontal missing teeth & 4.721 & 0.000 & 0.404 & 0.000 \\
\hline \multicolumn{5}{|l|}{ Caries (base: less than 6) } \\
\hline $6-11$ & 1.784 & 0.036 & 0.165 & 0.005 \\
\hline 12 or more & 7.032 & 0.001 & 0.607 & 0.000 \\
\hline \multicolumn{5}{|l|}{ Teeth lost by caries } \\
\hline $6-11$ & 3.445 & 0.000 & 0.284 & 0.000 \\
\hline 12 or more & 5.171 & 0.000 & 0.443 & 0.000 \\
\hline Malocclusion & 1.291 & 0.078 & 0.121 & 0.055 \\
\hline Inverse Mills ratio (IMR) & -3.782 & 0.131 & & \\
\hline Observations & 1,394 & & 1,394 & \\
\hline LR test indep equations & & & 4.21 & 0.04 \\
\hline
\end{tabular}

in $\mathrm{SPOH}$, with OHIP-14 scores that improve discretely only when individuals overcome the lowest income level. We also find an educational gradient in $\mathrm{SPOH}$, even after controlling for proxies for material resources and biological factors.

\section{Gradients in selected SPOH dimensions}

Socioeconomic indicators could impact differently the distinct dimensions of SPOH. We now explore socioeconomic gradients in eight selected SPOH question scores. We focus on functional limitations and physical pain, in addition to psychological and social interaction impairments. We present the results in Table 5, including controls for oral health conditions as in Table 4, and present the estimates using the ordered response twoequation procedure. ${ }^{3}$

We find no statistically significant correlation between FONASA categories, education or children at home and the functional limitations and physical pain scores. We do find steep income and educational gradients for all of the other selected questions. FONASA categories are nonlinearly associated with these specific scores, with a threshold effect that separates the lowest public health insurance group from the remainder of the population. The number of small children in households is also a statistically significant determinant of these OHIP-14 dimensions. 


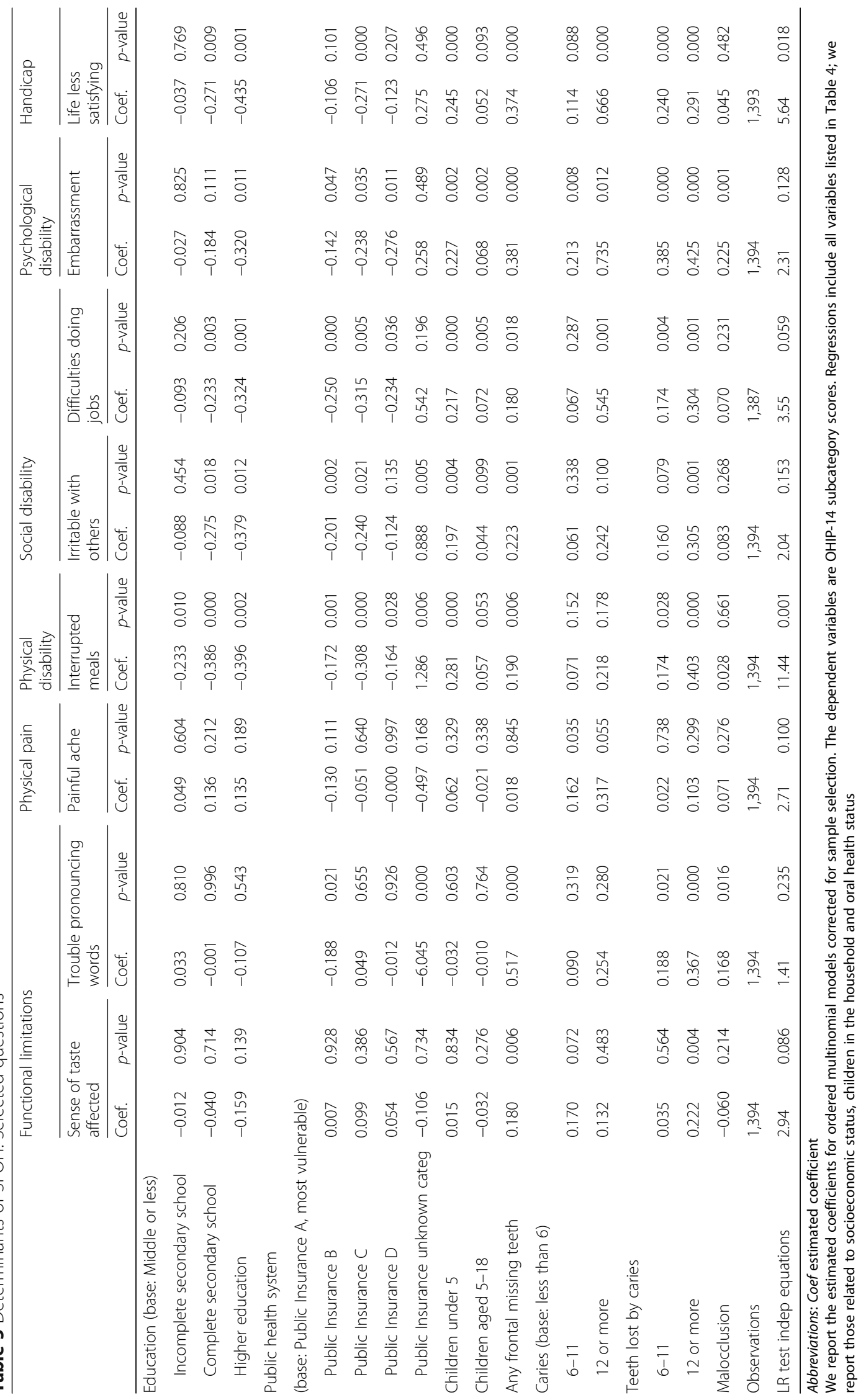


Oral health impairment variables are also significant. Some have larger impacts on specific questions. For example, missing front teeth is an impairment that is very different from caries or malocclusion in terms of social significance and it has a larger impact on life satisfaction and on embarrassment.

In sum, after controlling for oral health indicators, our results imply that the psychological and social dimensions, rather than the physical limitation dimensions, seem to be responsible for the OHIP-14 gradients. Being embarrassed, irritable with others and feeling that life is less satisfying all show significant correlations with educational attainment and with FONASA categories. In all these cases, we again find that while individuals affiliated with FONASA B to D categories are significantly better off than those affiliated to FONASA A, their estimated coefficients are not statistically different between them ( $p=0.46, p=0.50$, and $p=0.12$, respectively).

\section{Discussion}

This study investigated the association between selfperceived oral health and socioeconomic background among Chilean adults. Data comes from the baseline survey of a program offering free dental care services to low income individuals.

One relevant advantage of the survey is its rich information on clinically assessed oral health, self-perceived oral health, self-esteem, socioeconomic background and demographic variables. One limitation, however, is the exclusion of high-income households, precluding us from estimating the full socioeconomic gradient.

This sample, although not representative of the general population, should come close to the public policy target. That is, the estimation results should be representative of the target population of a policy to provide free dental care (i.e., adults between 18 and 60 years of age affiliated with the public healthcare system), as we corrected for self-selection. Moreover, we show that correcting for the self-selected nature of the sample does not seem to qualitatively affect the estimates of the effect of socioeconomic background on self-perceived oral health.

We found socioeconomic gradients in self-perceived oral health when using the healthcare insurance plan as a proxy for income. This estimated socioeconomic gradient is non-linear: while individuals at the lowest level report poorer self-perceived oral health conditions, individuals in all other categories are significantly better off but with no statistical difference between them. One caveat, though, is that the expectation of free dental care services may have led survey respondents to alter their assessment of $\mathrm{SPOH}$. If this alteration of responses is correlated with income, the estimated gradient may be biased.

Although many studies have observed that individuals reporting worse oral-health related quality of life belong to low income households [12, 14, 15, 37-42], few studies have explicitly analysed the shape of the socioeconomic gradient [4].

Some studies assume a linear relationship between $\mathrm{SPOH}$ and household income in their multivariate analysis $[12,38,40]$. Other studies implicitly find a linear relationship between material resources and $\mathrm{SPOH}$. For instance, Wamala et al. [14] measure material deprivation by combining several socioeconomic indicators, to find that the share of individuals self-rating their oral health as poor or very poor reduces approximately by half as the social deprivation index is reduced in a step-wise manner.

Sanders et al. [4] also find an approximately linear relationship between the likelihood of a fair or poor selfrated oral health when an index of relative social status is used as proxy for material resources. However, and in line with our results, the study finds a threshold effect characterized by a discrete deterioration in self-perceived oral health when household income falls below the second quintile of its distribution. Gabardo et al. [16] find a similar threshold effect for census tract average income, but no gradient for income measured at the household level.

We also found gradients associated with educational attainment even after controlling for material resources. Other studies have also found an independent effect of schooling on oral health $[15,37,43]$, perhaps due to transitory income shocks that may be better captured by income variables and to health-related behavioural differences across educational groups.

The estimation results also show that $\mathrm{SPOH}$ is worse among women, and is negatively correlated to the presence of small children in the household. This probably occurs because of time- and money-consuming activities related to childcare, suggesting that individuals with small children could be an especially important target of oral health policies.

Finally, the analysis of specific SPOH scores suggests that the psychological and social dimensions, rather than the physical limitation dimensions, are responsible for the socioeconomic gradient in the OHIP-14 score. We find no statistically significant association between income measures or educational attainment and the functional limitations and physical pain scores. Trouble pronouncing words might be associated with specific missing teeth, a phenomenon that may not be correlated with income. In turn, the absence of a socioeconomic gradient for physical pain could be expected because tooth extraction is offered by the public system.

The analysis thus confirms the existence of a socioeconomic gradient in $\mathrm{SPOH}$ which we mainly attribute to inequalities in access to preventive dental services and to relatively complex oral health treatments like implants or prosthetics. Economically disadvantaged households face access barriers to dental healthcare in Chile given the 
limited public services provided and the costly and heterogeneous privately provided solutions. These barriers prevent even those with higher incomes within the public health insurance system to improve their $\mathrm{SPOH}$.

The literature has linked socioeconomic status and health through channels other than the availability of material resources, in particular psychological factors like psychosocial threats that lead to stress and which are unequally distributed in society, as well as statusrelated patterns of health behaviour [44]. These factors could also influence our results, as they may operate simultaneously.

To determine whether psychological and psychosocial resources explain the relationship between socioeconomic status and oral health, some authors have included variables such as self-esteem in multivariate models of self-perceived oral health [12, 16, 37, 45, 46]. In general, they find that psychosocial variables have explanatory power in oral health regressions and that their inclusion reduces the strength of the socioeconomic gradient. These results have been interpreted as evidence favouring a role for psychosocial factors in explaining oral health disparities. However, other authors have suggested that self-esteem and life satisfaction can be explained by self-rated oral health; i.e., that causality may run in the opposite direction $[47,48]$.

In our sample, the simple correlation of the OHIP-14 and each of its questions with the Rosenberg measure of self-esteem is negative and strong, so better levels of $\mathrm{SPOH}$ are associated with higher self-esteem. However, as both OHIP-14 and self-esteem are outcome variables, important concerns arise regarding a regression analysis that treats one of these variables as exogenous to the other, preventing us from performing such a statistical analysis. Still, we cannot rule out the hypothesis that psychological factors play a role in explaining the gradients.

Similarly, it is plausible that oral health inequalities and behaviour impact each other $[49,50]$. To avoid reverse causality problems, we have not included current behavioural variables in our models. In our sample there is a correlation between education and the frequency of dental care visits, but not between education and dental self-care behaviour such as frequent tooth brushing. If education serves partly as a proxy for long-term income, then this result is consistent with the hypothesis of unequal access to oral health services rather than with health-related behavioural differences. Sanders et al. [50] found a similar result.

We do control for clinical indicators of oral health that are partly determined by lifetime oral health behaviour. Socioeconomic gradients are attenuated after adjusting for oral status variables, although the socioeconomic background proxies remain significant and relevant predictors of self-perceived oral health.
Finally, there may also be concerns regarding whether the observed gradient is partly related to the effects of health on income as health affects the ability to work and to generate earnings. However, the kind of impairments we analyse in this study, such as tooth loss, are conditions that usually take a long time to reach their final stages [51]. Thus, if the causality runs from oral health status to income, then life course socioeconomic status, rather than present status should be identified as a main determinant of $\mathrm{SPOH}$. We have included educational attainment as a measure of long term earnings potential. We find independent correlations between $\mathrm{SPOH}$ and this measure of lifetime earnings, and between $\mathrm{SPOH}$ and current income measures.

\section{Conclusions}

This study contributes to the scant evidence on $\mathrm{SPOH}$ and socioeconomic status for developing countries. It also highlights the shape of this relationship in a context of unequal access to oral health services due to a combination of insufficient coverage in the public sector and costly and heterogeneous solutions in the private sector. Future research could theoretically and empirically examine the relationship between the organization of the oral healthcare system and the shape of the socioeconomic gradient.

This study analyses the case of Chile, a country that will probably make the transition to the group of developed countries in the next few decades. Thus, access inequalities could be even more pronounced in poorer countries and affect the shape of the socioeconomic gradient. For instance, access barriers could even extend to basic oral health services and not just to relatively complex procedures. If so, $\mathrm{SPOH}$ dimensions like those related to experiencing pain could show socioeconomic gradients, unlike in the Chilean case.

The appropriate policy interventions to reduce the observed inequities depend on the factors that explain the gradient. Although this study emphasizes inequity in access, the relevance of other channels that may link socioeconomic background to dental health should be examined more closely. Given the potential reverse causality problems, we cannot rule out the role these other channels play in explaining the variation in self-perceived oral health along the income distribution, in particular, of psychosocial factors. Future research could address these questions using experimental and quasi-experimental variation in access to dental care. ${ }^{4}$

\section{Endnotes}

${ }^{1}$ Results of the program evaluation are in Gallego et al., in progress [52].

${ }^{2}$ We use health insurance categories instead of income as a proxy for material resources because we suspect household income is underreported in our baseline sample, 
particularly for higher income individuals within the public health insurance system.

${ }^{3}$ The linear model results yield similar conclusions and are available upon request.

${ }^{4}$ For instance, Gallego et al. [52] analyse the impact of oral health on both SPOH and the Rosenberg scores in the context of an experimental design constructed using the sample of this study.

\section{Additional file}

Additional file 1: Supporting Information: Determinants of participation in the sample. Table S1. Probability of participating in the baseline survey sample. (DOCX $39 \mathrm{~kb}$ )

\section{Abbreviations}

OLS: Ordinary least squares; SPOH: Self-perceived oral health

\section{Acknowledgements}

The authors thank Elizabeth Coble, Michael Eddy and Elizabeth Weber for their excellent assistance and Guillermo Paraje for his comments and suggestions.

Pontificia Universidad Católica de Chile; London School of Economics and Political Science; Pontificia Universidad Católica de Chile; Universidad Adolfo Ibáñez and Núcleo Milenio Modelos de Crisis (NS 130017); Brown University. Corresponding author: Andrea Repetto, andrea.repetto@uai.cl.

\section{Funding}

The authors gratefully acknowledge FONDECYT Project \#1120539 for financial support.

\section{Availability of data and materials}

The dataset analysed in the current study is available from the corresponding author on reasonable request. The CASEN 2011 dataset can be requested from the Chilean Ministerio de Desarrollo Social at http:// observatorio.ministeriodesarrollosocial.gob.cl/casen_obj.php.

\section{Authors' contributions}

FG developed the original research question. $C L, L P$ and DV carried out the literature review. AR and DV ran the econometric analysis. FG, AR and DV interpreted the results and drafted the results and the discussion. All authors contributed to the revisions of the text and read and approved the final manuscript.

\section{Competing interests}

The authors declare that they have no competing interests.

\section{Ethics approval and consent to participate}

Ethics approval for the study was obtained from the Human Ethics and Research Committee of the Economics Department of Pontificia Universidad Católica de Chile.

\footnotetext{
Author details

'Department of Economics, Pontificia Universidad Católica de Chile, Vicuña Mackenna 4860, Macul, Santiago, Chile. ${ }^{2}$ Department of Philosophy, Logic and Scientific Method, London School of Economics and Political Science, Houghton Street, London WC2A 2AE, UK. ${ }^{3}$ School of Dentistry, Pontificia Universidad Católica de Chile, Vicuña Mackenna 4860, Macul, Santiago, Chile. ${ }^{4}$ School of Government, Universidad Adolfo Ibáñez, and Núcleo Milenio Modelos de Crisis (NS 130017), Diagonal Las Torres 2640, 234A Peñalolén, Santiago, Chile. ${ }^{5}$ Department of Economics, Brown University, 64 Waterman Street, Providence, RI 02912, USA.
}

Received: 10 September 2016 Accepted: 9 January 2017 Published online: 21 January 2017

\section{References}

1. Allen PF. Assessment of oral health related quality of life. Health Qual Life Outcomes. 2003;1(1):40.

2. Gift HC, Reisine ST, Larach DC. The social impact of dental problems and visits. Am J Public Health. 1992;82(12):1663-8.

3. Slade GD, Nuttall N, Sanders AE, Steele JG, Allen PF, Lahti S. Impacts of oral disorders in the United Kingdom and Australia. Br Dent J. 2005;198(8):489-93.

4. Sanders AE, Slade GD, Turrel G, Spencer AJ, Marcenes W. The shape of the socioeconomic-oral health gradient: implications for theoretical explanations. Community Dent Oral Epidemiol. 2006;34(4):310-9.

5. Lamster IB, Lalla E, Borgnakke WS, Taylor GW. The relationship between oral health and diabetes mellitus. J Am Dent Assoc. 2008;139(S5):19S-24S.

6. Glied S, Niedell M. The economic value of teeth. J Hum Resour. 2010; 45(2):468-96

7. Walls AW, Steele JG, Sheiham A, Marcenes W, Moynihan PJ. Oral health and nutrition in older people. J Public Health Dent. 2000;60(4):304-7.

8. Ritchie CS, Joshipura K, Hung HC, Douglass CW. Nutrition as a mediator in the relation between oral and systemic disease: associations between specific measures of adult oral health and nutrition outcomes. Crit Rev Oral Biol Med. 2002;13(3):291-300.

9. Reisine ST. Dental health and public policy: the social impact of dental disease. Am J Public Health. 1985;75(1):27-30.

10. Jones JA, Orner MB, Spiro A, Kressin NR. Tooth loss and dentures: patients' perspectives. Int Dent J. 2003;53(S5):327-34.

11. McKeown L. Social relations and breath odour. Int J Dent Hyg. 2003; 1(4):213-7.

12. Locker D. Self-esteem and socioeconomic disparities in self-perceived oral health. J Public Health Dent. 2009;69(1):1-8.

13. Garbin Neumann D, Quiñonez C (2014) A comparative analysis of oral health care systems in the United States, United Kingdom, France, Canada, and Brazil. NCOHR Working Paper Series. http://ncohr-rcrsb.ca/knowledgesharing/working-paper-series/content/garbinneumann.pdf.

14. Wamala S, Merlo J, Boström G. Inequity in access to dental care services explains current socioeconomic disparities in oral health: the Swedish National Surveys of Public Health 2004-2005. J Epidemiol Community Health. 2006:60(12):1027-33.

15. Sabbah W, Tsakos G, Chandola T, Sheiham A, Watt RG. Social gradients in oral and general health. J Dent Res. 2007:86(10):996-2.

16. Gabardo MCL, Moysés SJ, Moysés ST, Olandoski M, Olinto MTA, Patussi MP. Multilevel analysis of self-perception in oral health and associated factors in Southern Brazilian adults: a cross-sectional study. Cadernos Saúde Pública. 2015;31(1):49-59.

17. Superintendencia de Salud. ¿A qué tipo de atención dental tienen derecho los afiliados del Fonasa? 2014. http://www.supersalud.gob.cl/consultas/570/ w3-article-2378.html.

18. Vásquez F, Paraje G, Estay M. Income-related inequality in health and health care utilization in Chile, 2000-2009. Rev Panam Salud Publica. 2013:33(2):98-106.

19. Van Dooerslaer E, Masseria C. Income-related inequality in the use of medical care in 21 OECD countries. Paris: Organisation of Economic Cooperation and Development; 2004

20. Slade GD. Derivation and validation of a short form oral health impact profile. Community Dent Oral Epidemiol. 1997;25:284-90.

21. López R, Baelum V. Spanish version of the oral health impact profile (OHIPSp). BMC Oral Health. 2006;6:11

22. Rosenberg M. Society and the adolescent self-image. Princeton: Princeton University Press; 1965.

23. Rojas-Barahona CA, Zegers B, Förster CE. La escala de autoestima de Rosenberg: validación para Chile en una muestra de jóvenes adultos, adultos y adultos mayores. Rev Med Chil. 2009;137:791-800.

24. World Health Organization. Oral health survey basic methods, Spanish. 4th ed. 1997.

25. Ministry of Social Development Chile. Encuesta de caracterización nacional CASEN 2011. 2011. http://observatorio.ministeriodesarrollosocial.gob.cl/ casen/casen_obj.php.

26. Johnson DR, Creech JC. Ordinal measures in multiple indicator models: a simulation study of categorization error. Am Sociol Rev. 1983:48(3):398-407.

27. Muthén B, Kaplan D. A comparison of some methodologies for the factor analysis of non-normal Likert variables. Br J Math Stat Psychol. 1985:38(2):171-89.

28. Taylor AB, West SG, Aiken LS. Loss of power in logistic, ordinal logistic, and probit regression when an outcome variable is coarsely categorized. Educ Psychol Meas. 2006;66(2):228-39. 
29. McKelvey RD, Zavoina W. A statistical model for the analysis of ordinal level dependent variables. J Math Soc. 1975;4(1):103-20.

30. Wooldridge J. Econometric Analysis of Cross Section and Panel Data. The MIT Press. 2010.

31. Angrist JD, Pischke JS. Mostly harmless econometrics: an empiricist's companion. Princeton: Princeton University Press; 2009.

32. Heckman JJ. Sample selection bias as a specification error. Econometrica. 1979;47(1):153-61.

33. De Luca G, Perotti V. Estimation of ordered response models with sample selection. Stata J. 2011;11(2):213-39.

34. Sapelli C, Vial B. Self-selection and moral hazard in Chilean health insurance. J Health Econ. 2003;22(3):459-76.

35. Paraje G, Vásquez $F$. Health equity in an unequal country: the use of medical services in Chile. Int J Equity Health. 2012;11:81.

36. Ministry of Health Chile. Diagnóstico de situación de salud bucal. 2010. http:// web.minsal.cl/portal/ur//item/7dc33dfobb34ec58e0400101 1e011c36.pdf.

37. Finlayson TL, Williams DR, Siefert K, Jackson JS, Nowjack-Raymer R. Oral health disparities and psychosocial correlates of self-rated oral health in the National Survey of American Life. Am J Public Health. 2010;100(S1):S246-55.

38. Sabbah W, Tsakos G, Sheiham A, Watt RG. The role of health-related behaviors in the socioeconomic disparities in oral health. Soc Sci Med. 2009; 68(2):298-303.

39. Tsakos G, Demakakos P, Breeze E, Watt RG. Social gradients in oral health in older adults: findings from the English longitudinal survey of aging. Am J Public Health. 2011;101(10):1892-9.

40. Nanayakkara V, Renzaho A, Oldenburg B, Ekanayake L. Ethnic and socioeconomic disparities in oral health outcomes and quality of life among Sri Lankan preschoolers: a cross-sectional study. Int J Equity Health. 2013;12:89.

41. Griffin SO, Jones JA, Brunson D, Griffin PM, Bailey WD. Burden of oral disease among older adults and implications for public health priorities. Am J Public Health. 2012;102(3):411-8.

42. Constante HM, Bastos JL, Peres KG, Peres MA. Socio-demographic and behavioural inequalities in the impact of dental pain among adults: a population-based study. Community Dent Oral Epidemiol. 2012;40(6):498-506.

43. Borrell LN, Burt BA, Neighbors HW, Taylor GW. Social factors and periodontitis in an older population. Am J Public Health. 2004;94:748-54.

44. Sisson KL. Theoretical explanations for social inequalities in oral health. Community Dent Oral Epidemiol. 2007;35:81-8.

45. Sanders AE, Spencer AJ. Why do poor adults rate their oral health poorly? Aust Dent J. 2005;50(3):161-7.

46. Sanders AE, Spencer AJ. Childhood circumstances, psychosocial factor and the social impact of adult oral health. Community Dent Oral Epidemiol. 2005:33:370-7.

47. Locker D, Matear D, Stephens M, Jokovic A. Oral health-related quality of life of a population of medically compromised elderly people. Community Dent Health. 2002;19(2):90-7.

48. Benyamini $Y$, Leventhal $H$, Leventhal EA. Self-rated oral health as an independent predictor of self-rated general health, self-esteem and life satisfaction. Soc Sci Med. 2004;59(5):1109-16.

49. López R, Fernández O, Baelum V. Social gradients in periodontal disease among adolescents. Community Dent Oral Epidemiol. 2006;34:184-96.

50. Sanders AE, Spencer AJ, Slade GD. Evaluating the role of dental behaviour in oral health inequalities. Community Dent Oral Epidemiol. 2006;34(1):71-9.

51. Tonetti MS, Steffen P, Muller-Campanile V, Suvan J, Lang NP. Initia extractions and tooth loss during supportive care in a periodontal population seeking comprehensive care. J Clin Periodontol. 2000; 27(11):824-31.

52. Gallego F, Larroulet C, Repetto A. What is behind her smile?: Looks, selfesteem, and labor market outcomes. Mimeo. (in progress). Santiago: Pontificia Universidad Católica de Chile.

\section{Submit your next manuscript to BioMed Central and we will help you at every step:}

- We accept pre-submission inquiries

- Our selector tool helps you to find the most relevant journal

- We provide round the clock customer support

- Convenient online submission

- Thorough peer review

- Inclusion in PubMed and all major indexing services

- Maximum visibility for your research

Submit your manuscript at www.biomedcentral.com/submit
Biomed Central 